\title{
Pilates versus resistance training on trunk strength and balance adaptations in older women: A randomised controlled trial
}

\author{
María Carrasco-Poyatos ${ }^{\text {Corresp., } 1}$, Domingo J Ramos-Campo ${ }^{2}$, Jacobo A Rubio-Arias ${ }^{2}$ \\ 1 Department of Education. Health and Public Administration Research Center, Universidad de Almería, Almería, Spain \\ 2 Department of Physical Activity and Sport Sciences. UCAM Research Centre for High Performance Sport, Universidad Católica San Antonio, Murcia, Spain \\ Corresponding Author: María Carrasco-Poyatos \\ Email address: carrasco@ual.es
}

Background. The neuromuscular decline impact in old women functional independence is determining the necessity to implement new strategies focused on core strength training and postural stability maintenance to promote healthy ageing. Objectives. To define whether Pilates or resistance training is better at improving a) core isometric and isokinetic muscular strength, and b) static and dynamic balance, in older women. Methods. This was a cluster randomized controlled trial. Physically independent older women (60-80 years) from day centres were randomly allocated to Pilates, Muscular and Control Groups (PG, MG and CG) using block randomization method. Only the research staff performing the assessment and statistical analysis were blinded. Exercise groups trained twice a week (1 hour per session) for 18 weeks in a moderate-to-vigorous intensity. Core strength (primary outcome): trunk and hip isometric and hip isokinetic muscular strength (Biodex System III Pro Isokinetic Dynamometer), alongside one leg static balance (portable force platform Kistler 9286AA) and dynamic balance (Timed Up and Go) were assessed. Results. Sixty participants were randomized (PG, $n=20 ; M G, n=20 ; C G, n=20$ ) and forty-nine completed the trial ( $P G, n=16 ; M G, n=19 ; C G, n=14)$. Regarding hip isometric extension strength, PG was statistically better than CG $(P=0.004)$. There were no differences between groups regarding isokinetic strength or balance. Intra-group comparisons showed significant improvements $(P<$ 0.05 ) in the dynamic balance and trunk and hip isometric extension strength for PG and MG, whereas every hip isokinetic measurement was improved in MG. Exercise programs did not produce any adverse event. Conclusions. The Pilates training program was more effective for improving isometric hip and trunk extension strength, while the Muscular training program generated greater benefits on trunk and hip isokinetic strength. Moreover, both training programmes showed moderate effects for the Timed Up and Go.

The trial was registered at ClinicalTrials.gov (identifier: NCT02506491). 
María Carrasco-Poyatos ${ }^{1}$, Domingo J. Ramos-Campo ${ }^{2}$, Jacobo A. Rubio-Arias ${ }^{2}$

${ }^{1}$ Department of Education. Health and Public Administration Research Center, Universidad de Almería, La Cañada de San Urbano, Almería, Spain

2 Department of Physical Activity and Sport Sciences. UCAM Research Centre for High

Corresponding Author:

María Carrasco-Poyatos ${ }^{1}$

Carretera Sacramento s/n., La Cañada de San Urbano, Almería, 04120, Spain.

Email address: carrasco@ual.es

\section{Abstract}

Background. The neuromuscular decline impact in old women functional independence is determining the necessity to implement new strategies focused on trunk strength training and postural stability maintenance to promote healthy ageing.

Objectives. To define whether Pilates or resistance training is better at improving a) trunk isometric and isokinetic muscular strength, and b) static and dynamic balance, in older women.

Methods. This was a cluster randomized controlled trial. Physically independent older women (60-80 years) from day centres were randomly allocated to Pilates, Muscular and Control Groups (PG, MG and CG, respectively) using block randomization method. Only the research staff performing the assessment and statistical analysis were blinded. Exercise groups trained twice a week (1 hour per session) for 18 weeks in a moderate-to-vigorous intensity. Trunk strength (primary outcome): trunk and hip isometric and hip isokinetic muscular strength (Biodex System III Pro Isokinetic Dynamometer), alongside one leg static balance (portable force platform Kistler 9286AA) and dynamic balance (Timed Up and Go) were assessed. completed the trial $(\mathrm{PG}, \mathrm{n}=16 ; \mathrm{MG}, \mathrm{n}=19 ; \mathrm{CG}, \mathrm{n}=14)$. Regarding hip isometric extension strength, PG was statistically better than CG $(P=0.004)$. There were no differences between 
35 groups regarding isokinetic strength or balance. Intra-group comparisons showed significant 36 improvements $(P<0.05)$ in the dynamic balance and trunk and hip isometric extension strength 37 for $\mathrm{PG}$ and $\mathrm{MG}$, whereas every hip isokinetic measurement was improved in MG. Exercise 38 programs did not produce any adverse event.

39 Conclusions. The Pilates training program was more effective for improving isometric hip and 40 trunk extension strength, while the Muscular training program generated greater benefits on

41 42 43

44 45

\section{6}

47 48 49 50 51

52 53 54 55 56 trunk and hip isokinetic strength. Moreover, both training programmes showed moderate effects for the Timed Up and Go.

The trial was registered at ClinicalTrials.gov (identifier: NCT02506491).

Funding: This work was supported by the San Antonio Catholic University (PMAFI/24/14).

\section{Introduction}

The female gender is associated with lower odds of healthy ageing with advancing age (1). Due to their age-related hormone changes (i.e. menopause), women are more affected by this neuromuscular decline, which contributes to a worsening of functional independence and disability (2) and an increased risk of hospitalization and mortality (3). Moreover, sarcopenia and muscle strength are negatively associated with balance and the risk and fear of falling in older women (4), thus falls and injuries are more frequent in women than in men (5).

To reach the status of healthy ageing, developing and maintaining functional ability that enables well-being is required. Thus, one of the primary objectives for functional maintenance in older women should be keeping postural stability (i.e. controlling the body's centre of pressure) (6) and improving core strength, because research has shown a strong association between core strength and balance in the older generation (7). In this way, the timed up and go test is a quick way to determine the influential balance issues on elderlies' daily lives and for the prediction of future falls (8). In addition, low concentric muscle strength, assessed by isokinetic evaluation is the most accurate method to determine muscle activity (9) and low values of isometric strength have been associated with higher risk of falls (10). Moreover, the decrease of the back muscle strength may lead to the quality of life decline and the falls increment in postmenopausal women with osteoporosis (11). Thus, the measurement of isokinetic and isometric hip and trunk strength can offer important information about physical factors related to healthy ageing. 
66 One of the most common types of exercise included in training for older people is

67 multicomponent training as a combination of two or more of the following exercises: muscle 68 resistance/strength, walking/endurance, balance and/or flexibility. Some systematic reviews and 69 meta-analytical studies on this topic (12) demonstrate a positive effect of strength training on 70 cardiorespiratory fitness, body composition, metabolic outcomes, functional status, cognitive 71 performance and quality of life in older people. Furthermore, a resistance training exercise 72 program that focuses on the centre of the body also results in positive effects on static (13) and 73 dynamic balance $(13,14)$ and improves the isokinetic strength of the knee $(13)$.

74 Furthermore, during recent years a new type of training program called Pilates has been included 75 as an effective method for improving physiological and psychological function. Some systematic 76 reviews with meta-analysis showed strong evidence for Pilates training to improve static and 77 dynamic balance $(16,17)$ and lower limb strength, hip and lower back flexibility, and 78 cardiovascular endurance (16) in older adults. Moreover, studies involving older women indicate that Pilates-based exercise programs enhance isometric and isokinetic strength (18-21).

80

81

82 83

84 85 86

However, there is not enough evidence regarding the differences between two core exercise programs, such as resistance training or Pilates, on static or dynamic balance and core strength in this population to make the appropriate recommendations. Moreover, there is also a lack of information concerning core isometric or isokinetic muscular strength, as most studies have measured other corporal regions. For these reasons, the objectives of the present study were to determine what type of training creates greater adaptations in a) core isometric and isokinetic muscular strength (primary outcomes), and b) static and dynamic balance (secondary outcomes), in older women. Our hypothesis was that Pilates training would exacerbate increases in static and dynamic balance and isometric trunk and hip strength. We additionally hypothesized that resistance training would promote greater adaptations in isokinetic trunk and hip strength and dynamic balance.

\section{Materials \& Methods}

\subsection{Design}

This was a 18-week quasi-experimental randomized controlled trial in which independent older women were assigned to a Pilates Group (PG; $n=20)$, a Muscular Group (MG; $n=20)$ or a noexercise Control Group (CG; $n=20)$. The trial was managed by the Faculty of Sport at San Antonio Catholic University (UCAM), Murcia, Spain, and was approved by the UCAM ethics 
97 committee. It was registered with ClinicalTrials.gov (NCT02506491; available from 98 https://clinicaltrials.gov/show/NCT02506491), and the trial design followed Consort guidelines. 99 Before starting the study and owing to an expert revision, original primary and secondary 100 outcome measures were restructured in order to make the design more precise. This 101 reorganization caused a delay in the beginning of the measurement date, starting on January and 102 finishing on May (2016). Moreover, the final sample enrolled in the study was 60 instead of 80 103 women.

\section{2.2. Participants}

105 A total of 80 older women (60-80 years) were invited to participate in the study. They were 106 recruited from old people day centers from Murcia (Spain). These are centers were non 107 institutionalized old people achieve activities such as painting, shewing or gardening. A general 108 medical evaluation was accomplished to ensure they were physically and mentally able to 109 participate in the exercise programs. It included the control of age, the level of education, toxic 110 habits, medical treatment and/or diseases that can affect musculoskeletal or cardiovascular 111 systems (self-report), mental illness - measured with the Mini-Mental state (22)-, urinary 112 incontinence, the presence of oedema and high blood pressure, and the independence to develop 113 basic and instrumental activities of daily living, measured with Katz and Lawton and Brody 114 scales $(23,24)$. Inclusion criteria were: women 60-80 years old who were physically able to 115 develop the basic and instrumental activities of daily living and were without cognitive 116 impairment or diseases that can affect musculoskeletal or cardiovascular systems. The exclusion 117 criteria were: women who were currently participating or had previously participated in a 118 structured Pilates or resistance training exercise program in the past 3 months and those with a 119 visual or auditory impairment not corrected with glasses or a hearing aid. Participants also had to 120 maintain at least $80 \%$ (29 sessions) compliance with the exercise session. Sixteen women did not 121 meet the inclusion criteria and four refused to participate. In total 60 women were actually 122 enrolled in the study and randomly distributed into PG, MG and CG. All participants signed a 123 consent form before the beginning of the study. Data were collected at the UCAM high124 performance sport research centre.

\section{2.3. Interventions}

126 Participants allocated to PG or MG were required to train twice a week (1 hour per session) for 12718 weeks from January to May (2016). Women assigned to CG were encouraged to maintain 
128 their normal physical activity habits. The exercise programs were conducted by the same 129 accredited exercise expert who was certified in personal training and Pilates.

130 The programs were divided into a 2-week familiarization period and four 4-week mesocycles 131 that were designed to be progressively more challenging. An example of the training progression 132 and the exercises implemented can be seen in Table 1. The sessions were given in three phases: 133 (1) the warm-up, (2) the Pilates or resistance training exercise programs and (3) the cool-down. 134 Intensity was controlled using the OMNI-Resistance Exercise Scale of perceived exertion (25), 135 beginning at a moderate intensity (6-7 points) and finishing at a moderate-to-vigorous intensity 136 (8-9 points).

137 The Pilates and resistance training exercise programs were focused on the spine, hip and girdle 138 regions, stimulating the muscles in a dynamic and static way and exercising the arms and legs. 139 Balance was an essential part of the standing exercises, and movements were always coordinated 140 with breathing. In addition, the Pilates exercise program also incorporated the principles of 141 Pilates, such as recruiting the body centre's deep stabilizers to prepare movement, keeping the 142 pelvis and the shoulder girdle in a neutral position to allow the extremities to disassociate from 143 the trunk and being conscious of every aspect of all exercises to obtain correct and more valued 144 movements. An example of Pilates exercises is presented in Table S1.

\section{3.4. Outcomes}

146 The primary outcome measures were trunk and hip isometric and isokinetic strength. The 147 secondary outcome was balance. The test was performed in all participants before and after the exercise intervention programs. The pre-tests were accomplished in January over a 1-week 149 period.

\section{3.4.1. Primary outcomes}

151 Core strength was determined by trunk and hip isometric (Tisom and Hisom) and hip isokinetic 152 (Hisok) muscular flexion and extension strength. These parameters were assessed on a Biodex 153 System III Pro Isokinetic Dynamometer (Biodex Medical System, NY, USA). Before 154 measurements were taken, participants were asked to warm up on a bicycle ergometer for 5 155 minutes using a self-chosen resistance of 40-60 rpm (20-30 watts), followed by 5 minutes of 156 stretching exercises for the trunk and lower extremities (26). Isokinetic testing was performed 157 before isometric testing. For Hisok and Hisom assessments, participants lay supine on the dynamometer chair (27). The chest, pelvis and non-tested thigh were fixed to the dynamometer 
159 chair using straps, therefore only the dominant side was assessed. The rotation axis was set at the 160 level of the femoral joint (27). For Hisok, the range of movement in the tested hip was adapted to 161 the flexion capacity of each participant. For Hisom, the hip was fixed at $90^{\circ}$ flexion. For Tisom 162 assessment, participants were fixed in a standardized position (28) with the trunk fixed at $90^{\circ}$ 163 flexion. The rotation axis was set at the level of L5-S1 (29). For isokinetic testing, participants 164 executed five concentric-concentric contractions at low $(60 \%)$ and high $(120 \%$ s) velocity with 2

165 166 167 168 169 minutes of rest in-between. Prior to the test, a familiarization set of five submaximal repetitions was performed at each protocol speed. Following Steinhilber et al (26) and Meyer et al (27) for isometric testing, five sustained maximal voluntary isometric flexion and extension contractions of 5 seconds were executed with a 5-second rest period in-between. The parameters evaluated included peak trunk and hip isometric flexion and extension relative to weight (Tisom_Flw, Tisom_Exw, Hisom_Flw and Hisom_Exw), and also peak hip isokinetic flexion and extension at $60 \%$ and $120 \%$ relative to weight (Hisok_Fl60w, Hisok_Fl120w, Hisok_Ex60w and Hisok_Ex120w).

\subsubsection{Secondary outcomes}

Static balance (SB) was implemented by one leg test under single-task conditions and was assessed using a portable force platform (Kistler 9286AA. Kistler instrumente AG, Winterthur, Switzerland). The signal was transmitted to a computer at a sampling rate of $100 \mathrm{~Hz}$. The data were exported and processed in Excel (Microsoft Excel 2018 for Windows). Since there is no gold standard measure of balance (30), the most common single leg static balance protocol was implemented. Participants were barefoot and maintained an upright position with their hands hanging loosely down and their eyes open. Their gaze was fixed on a mark at eye level. Right and left single support was performed. The time (seconds) that they maintained the static position was measured. The displacement velocity of the center of pressure in the medio-lateral and antero-posterior planes, as well as the velocity moment, were calculated using the formula described elsewhere (31). The mean of the right and left support was calculated for the data analysis. Variables were: SB_Time (s), SB_Vml (mm/s), SB_Vap $(\mathrm{mm} / \mathrm{s})$, SB_Varea $\left(\mathrm{mm} / \mathrm{s}^{2}\right)$. Measurements were conducted in three 30-second trials with 1 minute of rest in-between. Dynamic balance was assessed using the 3-metre walk Timed Up and Go (TUG) test (32). Participants were given one TUG familiarization trial followed by two maximal trials in a fast velocity. The best time was used in the analyzes. 
190

191

192

193

194

195

196

197

198

199

200

201

202

203

204

205

206

207

208

209

210

211

212

213

214

215

216

217

218

219

220

\subsection{Sample size and power}

Calculations to establish sample size were performed using Rstudio 3.15.0 software. The significance level was set at $\alpha=0.05$. According to the standard deviation (SD) established for isometric trunk extension in a previous study (33) and an estimated error $(d)$ of $23 \mathrm{~N} / \mathrm{m}$, a valid sample size for a confidence interval (CI) of $95 \%$ was $46\left(n=\mathrm{CI}^{2} \times d^{2} / \mathrm{SD}^{2}\right)$. A total of 49 women completed the trial. The final sample size for each group obtained in our study $(\mathrm{PG}=16$, $\mathrm{MG}=19, \mathrm{CG}=14)$ will provide powers of $78 \%, 85 \%$ and $69 \%$ respectively if between and within a variance of 1 .

\subsection{Randomisation and blinding}

A block randomization method was used to allocate participants to the groups with equal sample sizes (PG, MG and $\mathrm{CG}, n=20$ ). This randomization method was chosen according to allocation of the specialized senior centres. Block size was determined by the research staff according to the statistical power provided. Blocks were chosen randomly to determine the participants' assignment into the groups. Following Kim (34), a randomization sequence was created using Excel 2016 (Microsoft, Redmond, WA, USA) with a 1:1 allocation using a random number table by one of the research staff member specialist in statistical analysis. Owing to the difficulty of blinding the participants and instructors in exercise trials, only the research staff performing the assessment and statistical analysis were blinded to the exercise group assignment. The allocation concealment method selected was central allocation.

\subsection{Statistical methods}

Statistical analyses were conducted using SPSS Statistics 23.0 (Armonk, NY, USA). Prior to data analysis, the Kolmogorov-Smirnov test was used to determine the normal distribution of the variables. Levene's test was also performed to determine the homogeneity of variance. Descriptive data are presented as mean \pm SD and range. Intention-to-treat analysis using last observation for missing data was conducted. To compare variables before the intervention, analysis of variance for repeated measures (ANOVA) was calculated (general linear model). To compare variables after the intervention, ANCOVA analyses with baseline values included as co-variables were used in order to adjust for potential baseline differences in the dependent variables. As additional analyses, Student's $t$-test for dependent samples was used to evaluate variables within groups. The standardized mean differences (Cohen's effect size) between groups (PG, MG and CG) were calculated together with the $95 \%$ confidence intervals (35). An effect 
221 size (ES) value of 0.20 indicates a small effect, 0.50 indicates a medium effect, and 0.8 indicates 222 a large effect (35). The level of significance was set to $P<0.05$.

\section{Results}

224 Figure 1 illustrates the participant flow during the protocol. The period of recruitment was from 225 September to December of 2016. The trial started in January 2016 and ended in May 2016. Table 2262 defines the characteristics of the participants at baseline for each group. At the end of the study 227 there were 16 participants in PG, 19 in MG and 14 in CG. The total participation average was of $22891.6 \%$.

229 The main analysis of the present research indicates that there was a significant training $\times$ group 230 difference $(P=0.005)$ in the isometric hip extension strength, with PG statistically different $231(\mathrm{P}=0.004)$ from $\mathrm{CG}$ (Table 3). There were no differences between groups regarding isokinetic 232 strength (Table 4) or balance (Table 5).

233 The additional analysis (intra-group) shows:

234

a) There was a significant improvement in trunk isometric extension in PG and MG, which was supported by a large effect size (PG: \%change $=18.7 \%, P=0.033, \mathrm{ES}=0.6$; $\mathrm{MG}$ : $\%$ change $=22.2 \%, P=0.019, \mathrm{ES}=0.82$ ). There was also a significant increase in hip isometric extension in both groups, with a moderate effect size in PG (PG: \%change = $35.5 \%, P=0.0003, \mathrm{ES}=2.06 ; \mathrm{MG}$ \% $\%$ change $=21.4 \%, P=0.001, \mathrm{ES}=0.61)($ Table 6$)$.

240

b) Table 6 shows the isokinetic strength measurements. Hip isokinetic flexion was significantly improved in PG (Hisok_Fl60w: \%change $=18.9 \%, P=0.014$, ES $=0.85$; Hisok_Fl120w: \%change $=18.3 \%, P=0.038, \mathrm{ES}=0.57$ ) and every hip isokinetic variable was significantly improved in MG (Hisok_Fl60w: \%change $=33.1 \%, P=$ $0.000004, \mathrm{ES}=1.02$; Hisok_F1120w: \%change $=33.9 \%, P=0.0001$, ES $=0.95$; Hisok_Ex60w: $\%$ change $=31.4 \%, P=0.001, \mathrm{ES}=1.03$; Hisok_Ex120w: \%change $=$ $26.6 \%, P=0.031, \mathrm{ES}=0.7)$.

Regarding safety, there were registered adverse events only in CG. The illnesses that caused the

c) The TUG test results improved significantly in both PG and MG (PG: \%change $=4.8 \%$, $P=0.018, \mathrm{ES}=0.39 ; \mathrm{MG}: \%$ change $=12.3 \%, P=0.002, \mathrm{ES}=0.5)$. four women lost to follow-up in CG were all related to musculoskeletal diseases: two broken wrists after a fall and two sprained ankles. Exercise programs did not produce any adverse event. 


\section{Discussion}

253 The main objective of the present study was to define whether Pilates or traditional resistance 254 training was better at improving trunk strength and balance in older women. After the 18-week 255 intervention, the Pilates group obtained better results than the control group regarding hip 256 isometric extension strength. There were no other statistical differences between groups in the 257 other isometric or isokinetic trunk and hip variables as well as in the static and dynamic balance. 258 As additional results, at the end of the study the Pilates and Muscular groups improved 259 significantly in dynamic balance and trunk and hip isometric extension strength. Moreover, the 260 Pilates group significantly increased the isokinetic hip flexion and the Muscular group 261 significantly increased every isokinetic variable.

262 The main result of this study is that scores obtained in the Pilates group were statistically greater 263 than the control group regarding hip isometric extension strength, with a difference of $40.82 \mathrm{~N} / \mathrm{m}$ 264 between groups. In this regard, it should be highlighted that our additional results showed a 265 significant increase in isometric hip extension strength for both the Pilates and Muscular groups 266 but this was not enough to produce significant differences between the Muscular and control 267 group. A possible explanation for this might be that Muscular group showed higher basal values $268(111.83 \pm 47.8 \mathrm{~N} / \mathrm{m})$ than the Control Group $(106.81 \pm 30.3 \mathrm{~N} / \mathrm{m})$ or Pilates Group $(100.19 \pm 19$ $269 \mathrm{~N} / \mathrm{m})$.

270 On the other hand, this result could be associated with the training methodology conducted in the 271 Pilates program. Although Pilates and traditional resistance exercise programs contained similar 272 spine, hip and girdle region exercises, stimulating the muscles in a dynamic and static way, in the 273 Pilates exercise program training instructions were always focused on the Pilates principles (15) 274 and a prone or supine body posture was adopted habitually. The more controlled and accurate 275 movement accomplished in the Pilates group can assist better neural adaptations (i.e. the 276 coordination of muscle recruitment) that could subsequently be transferred to movement control 277 (36): following Carroll et al. (36), this fact and the more frequent body-lying posture could have 278 enhanced the performance in related functional tasks. It can thus be suggested that due to the 279 Pilates specific training methodology, women in the Pilates group showed higher values (larger 280 effect) than women in the Muscular group (moderate effect) regarding isometric hip extension 281 test. 
282 Thus, despite that Pilates exercises entails dynamic exercises, the exercises conducted in the 283 Pilates program entailed greater use of the hip extension muscles in an isometric way, which 284 explains the increased isometric hip extension strength. In the meta-analysis of Bueno de Souza 285 (16), it was pointed out that Pilates is effective for improving strength in older individuals. There 286 were just three studies where core strength was measured $(23,27,28)$ but hip extension strength 287 was not registered in any case and an isokinetic dynamometer was only used in one of the 288 studies. In the study of Irez (37), a 14-week exercise program held 3 days per week, 60 minutes 289 per session, was accomplished in older individuals (aged 65 and over). Two exercise groups 290 were compared (a Pilates mat group and a walking group) alongside a control group. Isometric 291 hip flexion strength was measured with a manual muscle tester, showing statistical improvement 292 only for the Pilates group. However, differences between groups were not referred to in that 293 study. On the other hand, in the study of Donath et al. (38), the Pilates group was compared with 294 a multimodal balance training group and a control group. The interventions were conducted over 2958 weeks, with two sessions per week, 65 minutes per session in healthy seniors (75\% women; 296 mean age 69.1). In this case, the balance group was statistically better than the Pilates group 297 regarding isometric trunk extension strength, measured with the modified Sorensen test. 298 However, Markovic et al. (33) did not find any statistical difference in isometric trunk extension 299 strength between a Pilates group, a balance and core resistance training group and a control 300 group after an 8-week program three times per week, 60 minutes per session in women aged 6530179 years. These results are in accordance with those obtained in the present study regarding trunk 302 strength, but the hip scores are missing again.

303 It is important to know the prevalence of exercises regarding hip muscle in the Pilates protocols 304 and, to our knowledge, there are no other studies that provide such data. Moreover, from a 305 health-related point of view, hip isometric strength in women declines by an average of 1.31 $306 \mathrm{~kg} /$ year between the ages of 70 and 75 years, and $0.39 \mathrm{~kg} /$ year thereafter (39), with faster rates of 307 decline in hip strength predicting mortality (39). Furthermore, isometric hip strength is 308 associated with the incidence of lower-limb musculoskeletal injuries (40), leading to decreased 309 functional status. Isometric hip extension strength is a particular factor that distinguishes fallers 310 from non-fallers (41). Consequently, the Pilates exercise program used in the present study could 311 be recommended for promoting daily physical activity development in older women, 312 contributing to diminished risk of falling and a lower risk of dying in older women. 
313 Regarding the additional analysis results, there were significant improvements in isometric trunk 314 and hip extension and isokinetic hip flexion strength after the 18-week training period in the 315 Pilates and group. These findings are in accordance with other studies $(18,33,42)$. One 316 unexpected finding was that isokinetic hip extensor strength showed no improvement after the 317 Pilates program. This could indicate that there was a prevalence of exercises based on dynamic 318 hip flexion rather than dynamic hip extension in the Pilates program. Dynamic hip extensions 319 can only be conducted in prone or four-footed positions, which are more complex for older 320 women to adopt. This may lead to a lack of prone or four-footed position exercises in the Pilates 321 sessions, which should be addressed in Pilates protocols in order to avoid muscular imbalance.

322 For its part, Muscular program participants significantly increased either their trunk and hip 323 isometric extension or the trunk and hip isokinetic strength at $60 \% \mathrm{~s}$ and $120 \%$, which was 324 accompanied by a moderate to high effect sizes. The large increase in the Muscular group could 325 be attributed to greater neural mechanisms, as the exercises more frequently involved other parts 326 of the body (i.e. upper or lower extremities). It is well known that strength training can assist 327 neural adaptations (i.e. the coordination of muscle recruitment), which could subsequently be 328 transferred to movement control (36). Traditionally, mobility, balance and functionality 329 impairments in old people has been associated to aged-related lower extremities changes (43). 330 Nevertheless, trunk stability and strength could enhance old people mobility and functionality, 331 favoring the development of daily physical activities and reducing the risk of falling (44). In this 332 regard, Irez et al. (18) showed significant changes in dynamic balance, the sit and reach test, 333 muscle strength and a decreased risk of falling when integrating Pilates into an exercise program 334 using elastic resistance bands in older women. Hence combining the Muscular and the Pilates 335 programs could increase the functional performance and quality of life in older women.

336 Regarding static balance, and against our hypothesis, no changes were found in any of the 337 experimental groups after training and no differences were found between groups. In contrast, 338 Bird et al. (45) showed changes in static and dynamic balance following 5 weeks of Pilates 339 training. Kibar et al. (46), observed that an eight-week Pilates training program could improve 340 static balance, flexibility, abdominal muscle endurance, and abdominal and lumbar muscle 341 activity. In addition, strength training may increase balance in older people (47). In this way, a 342 previous systematic review (48) concluded that the inconsistent effect of the resistance training 343 programs on balance may be explained by several factors: the heterogeneity of cohort and 
344 balance tests, the variability in methodology of the balance test and the sample size, the 345 inadequate dose of resistance training and/or compliance to training, the lack of statistical power, 346 and that strength training alone is not robust enough to improve balance.

347 However, our results showed a significant improvement in the TUG test in both the 348 Pilates and the Muscular groups. These results are in line with previous Pilates $(19,49-51)$ and 349 traditional resistance training programs $(13,52)$. One possible explanation for these dynamic 350 balance improvements may be the increase in lower limb and abdominal strength and the 351 improved postural control (19). Pilates exercises are based on movement control, which can lead 352 to changes in the nervous system through alterations of synaptic connections and cortical 353 remapping (53). Pilates can also improve core stability and make an individual more 354 kinaesthetically aware of how to reduce faulty movement patterns (54), thus resulting in 355 improved motor control. In addition, a previous systematic review (55) regarding different exercise intervention showed that the TUG improved after the strength training period with an increment of $7.2-40 \%$. It was associated with increased strength in the lower limbs and 358 abdominal muscles and optimized postural control (53). Ours results suggest that Pilates training 359 and resistance training were effective to increase the mobility in older women and may 360 contribute to diminished fall rates.

361 The clinical implications of the present study are related to the hip muscle enhancement that 362 comes with Pilates training. Practicing Pilates twice a week ( 1 hour per session) for 18 weeks in 363 a moderate-to-vigorous intensity and increasing resistance with elastic bands controls age-related muscular decline and the associated lower-limb musculoskeletal injuries contributing to the risk of falling. This will also contribute to reduce the health care system spending. In this way, the Pilates program could be recommended by the sanitary, physiotherapist and sports personnel for improving hip strength and for diminishing the risk of falling in aged women. In addition, both training programmes showed a trend forward to improve functional and strength variables when compared to the control group. On the other hand, these results should be considered with several limitations. The non-blinding of participants and instructors affects the internal validity.

371 The external validity of the results could not be generalized because of the small sample size at 372 the end of the study. Controlling cognitive function or opening the age range could determine 373 any interaction regarding the results. Moreover, to follow more closely the exercises execution in 374 order to improve the quality performance and to check more frequently the working load 
375 adaptation of every participant should be taken into account in order to increase the exercise 376 programs strength and balance effects. Additionally, the number of flexion and extension-based 377 exercises should be controlled in order to avoid muscle imbalance.

\section{Conclusions}

379 According to the results obtained in the present study, the Pilates training program seems to be 380 more effective for improving isometric hip and trunk extension strength, and the Muscular 381 training program appear to have greater effects on trunk and hip isokinetic strength, with no 382 significant effects between groups. Additionally, both training programmes showed moderate effects for the Timed Up and Go. Nonetheless, studies with larger sample sizes and longer duration are necessary to clarify the effects of each of the trainings programs used.

\section{5}

386

387

388

389

390

391

392

393

394

395

396

397

398

399

400

401

402

403

404

405

406

\section{Acknowledgements}

This research was edited and proofreaded by Proof-Reading-Service.com (United Kingdom).

\section{References}

1. Rodríguez-Laso A, McLaughlin S, Undaneta E, Yanguas J. Defining and estimating healthy ageing in Spain: A cross-sectional study. Gerontol. 2018;52(2):388-98.

2. Newman AB, Kupelian V, Visser M, Simonsick E, Goodpaster B, Nevitt M, Kritchevsky S, Tylavsky F, Rubin S, Harris T. Sarcopenia: Alternative Definitions and Associations with Lower Extremity Function. J Am Geriatr Soc. 2003;51(11):1602-9.

3. Guadalupe-Grau A, Carnicero J, Losa-Reyna J, Tresguerres J, Gómez-Cabrera M, Castillo C, Alfaro-Acha A, Rosado-Artalejo C, Rodríguez-Mañas L, García-García FJ. Endocrinology of ageing from a muscle function point of view: results from the Toledo study for healthy ageing. J Am Med Dir Assoc. 2017;18(3):234-9.

4. Gadelha A, Neri S, Oliveira R, Bottaro M, David A, Vainshelboim B, Lima RM. Severity of sarcopenia is associated with postural balance and risk of falls in community-dwelling older women. Exp Ageing Res. 2018;20(1):1-12.

5. Gioffrè-Florio M, Murabito L, Visalli C, Pergolizzi F, Famà F. Trauma in elderly patients: a study of prevalence, comorbidities and gender differences.II. G di chirugia. 2018;39(1):3540.

6. Horak FB. Postural orientation and equilibrium: What do we need to know about neural control of balance to prevent falls? In: Age and Ageing. 2006.

7. Granacher U, Lacroix A, Muehlbauer T, Roettger K, Gollhofer A. Effects of core instability 
407

408

409

410

411

412

413

414

415

416

417

418

419

420

421

422

423

424

425

426

427

428

429

430

431

432

433

434

435

436

437

strength training on trunk muscle strength, spinal mobility, dynamic balance and functional mobility in older adults. Gerontology. 2013;59(2):105-13.

8. Sai AJ, Gallagher JC, Smith LM, Logsdon S. Fall predictors in the community dwelling elderly: A cross sectional and prospective cohort study. J Musculoskelet Neuronal Interact. 2010;10(2):142-50.

9. Eyigor S, Karapolat H, Durmaz B. Effects of a group-based exercise program on the physical performance, muscle strength and quality of life in older women. Arch Gerontol Geriatr. 2007;45(3):259-71.

10. Robinson B, Gordon J, Wallentine S, Visio M. Relationship between lower-extremity joint torque and the risk for falls in a group of community dwelling older adults. Physiother Theory Pract. 2004;20(3):155-73.

11. Miyakoshi N, Hongo M, Maekawa S, Ishikawa Y, Shimada Y, Itoi E. Back extensor strength and lumbar spinal mobility are predictors of quality of life in patients with postmenopausal osteoporosis. Osteoporos Int. 2007;18(10):1397-403.

12. Marín-Cascales E, Alcaraz PE, Ramos-Campo DJ, Rubio-Arias JA. Effects of multicomponent training on lean and bone mass in postmenopausal and older women: A systematic review. Menopause. 2018;25(3):346-56.

13. Marques EA, Mota J, Machado L, Sousa F, Coelho M, Moreira P, Carvalho J. Multicomponent training program with weight-bearing exercises elicits favorable bone density, muscle strength, and balance adaptations in older women. Calcif Tissue Int. 2011;88(2):117-29.

14. Seo B-D, Yun Y-D, Kim H-R, Lee S-H. Effect of 12-week Swiss Ball Exercise Program on Physical Fitness and Balance Ability of Elderly Women. J Phys Ther Sci. 2012;24(1):115.

15. Wells C, Kolt GS, Bialocerkowski A. Defining Pilates exercise: A systematic review. Vol. 20, Compl Ther Med. 2012. p. 253-62.

16. de Souza R, de Faria Marcon L, de Arruda A, Pontes Junior FL, de Melo RC. "Effects of Mat Pilates on Physical Functional Performance of Older Adults. Am J Phys Med Rehabil. $2017 ; 1$.

17. Moreno-Segura N, Igual-Camacho C, Ballester-Gil Y, Blasco-Igual MC, Blasco JM. The effects of the pilates training method on balance and falls of older adults: A systematic review 
438

439

440

441

442

443

444

445

446

447

448

449

450

451

452

453

454

455

456

457

458

459

460

461

462

463

464

465

466

467

468

and meta-analysis of randomized controlled trials. J Aging Phys Act. 2018;26(2):327-44.

18. Irez GB, Ozdemir RA, Evin R, Irez SG, Korkusuz F. Integrating pilates exercise into an exercise program for 65+ year-old women to reduce falls. J Sport Sci Med. 2011;10(1):10511.

19. Bergamin M, Gobbo S, Bullo V, Zanotto T, Vendramin B, Duregon F, Cugusi L, Camozzi V, Zaccaria M, Neunhaeuserer D, Ermolao A. Effects of a Pilates exercise program on muscle strength, postural control and body composition: results from a pilot study in a group of post-menopausal women. Age. 2015;37(6):118.

20. de Oliveira LC, Pires-Oliveira DA de A, Abucarub AC, Oliveira LS, de Oliveira RG. Pilates increases isokinetic muscular strength of the elbow flexor and extensor muscles of older women: A randomized controlled clinical trial. J Bodyw Mov Ther. 2016;

21. Oliveira LC, Oliveira RG, Pires-Oliveira DA de A. Pilates increases the isokinetic muscular strength of the knee extensors and flexors in elderly women. J Bodyw Mov Ther. 2017;21(4):815-22.

22. Folstein MF, Folstein SE, McHugh PR. "Mini-mental state". A practical method for grading the cognitive state of patients for the clinician. J Psychiatr Res. 1975;12(3):189-98.

23. Katz S, Ford AB, Moskowitz RW, Jackson BA, Jaffe MW. Studies of Illness in the Aged: The Index of ADL: A Standardized Measure of Biological and Psychosocial Function. JAMA J Am Med Assoc. 1963;185(12):914-9.

24. Lawton MP, Brody EM. Assessment of Older People: Self-Maintaining and Instrumental Activities of Daily Living. Gerontologist. 1969;9(3):179-86.

25. Robertson RJ, Goss FL, Rutkowski J, Lenz B, Dixon C, Timmer J, Frazee K, Dube J, Andreacci J. Concurrent validation of the OMNI perceived exertion scale for resistance exercise. Med Sci Sports Exerc. 2003;35(2):333-41.

26. Steinhilber B, Haupt G, Boeer J, Grau S, Krauss I. Erratum: Reproducibility of concentric isokinetic and isometric strength measurements at the hip in patients with hip osteoarthritis: A preliminary study (Isokinetics and Exercise Science (2011) 19 (39-46)). Vol. 20, Isok Exerc Sci. 2012. p. 147.

27. Meyer C, Corten K, Wesseling M, Peers K, Simon JP, Jonkers I, Desloovere K. Testretest reliability of innovated strength tests for hip muscles. PLoS One. 2013;8(11).

28. Sekendiz B, Altun Ö, Korkusuz F, Akin S. Effects of Pilates exercise on trunk strength, 
469

470

471

472

473

474

475

476

477

478

479

480

481

482

483

484

485

486

487

488

489

490

491

492

493

494

495

496

497

498

499

endurance and flexibility in sedentary adult females. J Bodyw Mov Ther. 2007;11(4):318-26.

29. Ester I, Garcia G, Maria S, Cavalcanti DB, Aoki MS. Isokinetic evaluation of the musculature involved in trunk flexion and extension : Pilates (C) method effect. Rev Bras Med do Esporte. 2004;10(6):491-3.

30. Heyward V, Gibson A. Advanced Fitness Assessment and Exercise Prescription 7th Edition With Online Video. Environments. 2014;552.

31. Ishizaki K, Mori N, Takeshima T, Fukuhara Y, Ijiri T, Kusumi M, Yasui K, Kowa H, Nakashima K. Static stabilometry in patients with migraine and tension-type headache during a headache-free period. Psychiatry Clin Neurosci. 2002;56(1):85-90.

32. Rikli R, Jones C. Senior Fitness Test Manual. Champaign IL: Human Kinetics; 2001.

33. Markovic G, Sarabon N, Greblo Z, Krizanic V. Effects of feedback-based balance and core resistance training vs. Pilates training on balance and muscle function in older women: A randomized-controlled trial. Arch Gerontol Geriatr. 2015;61(2):117-23.

34. Kim J, Shin W. How to do random allocation (randomization). Clin Orthop Surg. 2014;6(1):103-9.

35. Hopkins WG, Marshall SW, Batterham AM, Hanin J. Progressive statistics for studies in sports medicine and exercise science. Vol. 41, Med Sci Sport Exerc. 2009. p. 3-12.

36. Carroll TJ, Riek S, Carson RG. Neural adaptations to resistance training: implications for movement control. Sport Med. 2001;31(12):829-40.

37. Irez GB. The effects of different exercises on balance, fear and risk of falling among adults aged 65 and over. Anthropologist. 2014;18(1):129-34.

38. Donath L, Roth R, Hürlimann C, Zahner L, Faude O. Pilates vs. Balance Training in Health Community-Dwelling Seniors: A 3-arm, Randomized Controlled Trial. Int J Sports Med. 2016;37(3):202-10.

39. Xue Q-L, Beamer BA, Chaves PHM, Guralnik JM, Fried LP. Heterogeneity in rate of decline in grip, hip, and knee strength and the risk of all-cause mortality: the Women's Health and Aging Study II. J Am Geriatr Soc. 2010;58(11):2076-84.

40. Luedke LE, Heiderscheit BC, Williams DS, Rauh MJ. Association of isometric strength of hip and knee muscles with injury risk in high scholl cross crountry runners. Int J Sports Phys Ther. 2015;10(6):868-76.

41. Gafner SC, Bastiaenen CH, Ferrari S, Gold G, Terrier P, Hilfiker R. Hip muscle and 
500

501

502

503

504

505

506

507

508

509

510

511

512

513

514

515

516

517

518

519

520

521

522

523

524

525

526

527

528

529

530

hand-grip strength to differentiate between older fallers and non-fallers: A cross-sectional validity study. Clin Interv Aging. 2018;13:1-8.

42. Bertoli J, Dal Pupo J, Vaz MA, Detanico D, Biduski GM, de la Rocha Freitas C. Effects of Mat Pilates on hip and knee isokinetic torque parameters in elderly women. J Bodyw Mov Ther. 2017;

43. Fukagawa NK, Brown M, Sinacore DR, Host HH. The Relationship of Strength to Function in the Older Adult. Journals Gerontol Ser A Biol Sci Med Sci. 1995; 50: 55-59

44. Granacher U, Gollhofer A, Hortobágyi T, Kressig RW, Muehlbauer T. The importance of trunk muscle strength for balance, functional performance, and fall prevention in seniors: A systematic review. Sports Med. 2013; 43: 627-41.

45. Bird ML, Hill KD, Fell JW. A randomized controlled study investigating static and dynamic balance in older adults after training with pilates. Arch Phys Med Rehabil. 2012;93(1):43-9.

46. Kibar S, Yardimci FÖ, Evcik D, Ay S, Alhan A, Manço M, Ergin E. Can a pilates exercise program be effective on balance, flexibility and muscle endurance? A randomized controlled trial. J Sports Med Phys Fitness. 2016;56(10):1139-46.

47. Lee I-H, Park S. Balance Improvement by Strength Training for the Elderly. J Phys Ther Sci. 2014;25(12):1591-3.

48. Orr R, Raymond J, Fiatarone Singh M. Efficacy of Progressive Resistance Training on Balance Performance in Older Adults. Sport Med. 2008;38(4):317-43.

49. Bird M, Hill K, Ball M, Williams A. Effects of resistance- and flexibility- exercise interventions on balance and related measures in older adults. J Aging Phys Act. 2009;17(4):444-54.

50. Kaesler D, Mellifont R, Swete Kelly P, Taaffe D. A novel balance exercise program for postural stability in older adults: A pilot study. J Bodyw Mov Ther. 2008;11(1):37-43.

51. Mokhtari M, Nezakatalhossaini M, Esfarjani F. The effect of 12-week pilates exercises on depression and balance associated with falling in the elderly. Procedia Soc Behav Sci. 2013;70(12):1717-23.

52. Kang S, Hwang S, Klein AB, Kim SH. Multicomponent exercise for physical fitness of community-dwelling elderly women. J Phys Ther Sci. 2015;27(3):911-5.

53. Bolognini N, Pascual-Leone A, Fregni F. Using non-invasive brain stimulation to 
531 augment motor training-induced plasticity. J Neuroeng Rehabil. 2009;6(1).

532 54. Johnson EG, Larsen A, Ozawa H, Wilson CA, Kennedy KL. The effects of Pilates-based 533 exercise on dynamic balance in healthy adults. J Bodyw Mov Ther. 2007;11(3):238-42.

534 55. Cadore EL, Rodríguez-Mañas L, Sinclair A, Izquierdo M. Effects of Different Exercise 535 Interventions on Risk of Falls, Gait Ability, and Balance in Physically Frail Older Adults: 536 A Systematic Review. Rejuvenation Res. 2013;16(2):105-14. 
Figure 1

\section{Flow diagram of the progress of the randomized trial}

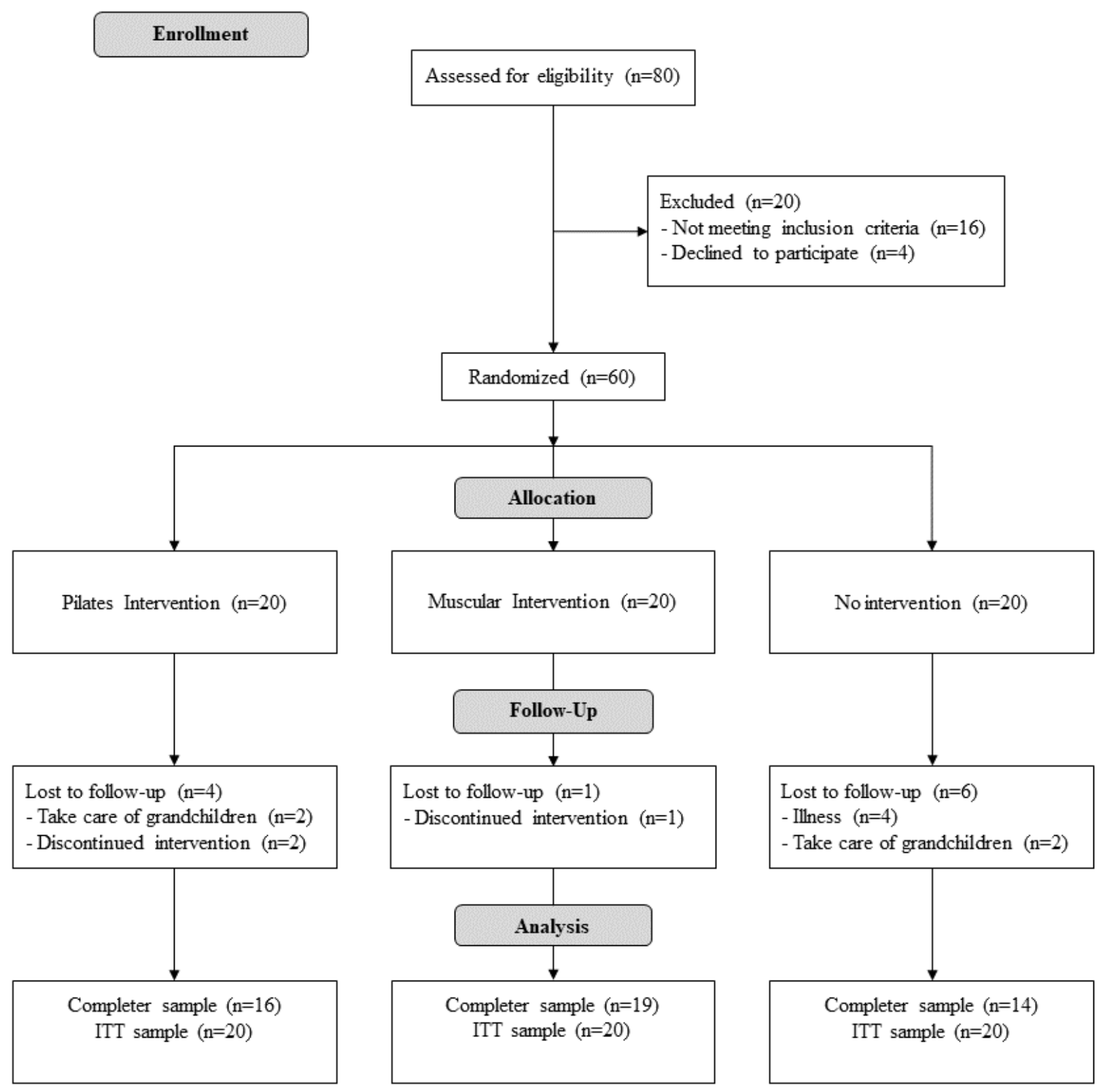




\section{Table $\mathbf{1}$ (on next page)}

Eighteen weeks training progression for Pilates and muscular groups 
1 Table 1: Eighteen weeks training progression for Pilates and muscular groups.

\begin{tabular}{|c|c|c|c|c|c|}
\hline MESOCYCLE & $\begin{array}{l}\text { SESSION EXAMPLE } \\
\text { FOR PILATES GROUP }\end{array}$ & $\begin{array}{c}\text { SESSION EXAMPLE } \\
\text { FOR MUSCULAR } \\
\text { GROUP }\end{array}$ & VOLUME & INTENSITY & DENSITY \\
\hline \multirow{3}{*}{$\begin{array}{l}\text { FAMILIARIZA } \\
\text { TION PERIOD } \\
\text { (WEEKS 1-2) }\end{array}$} & \multirow{3}{*}{$\begin{array}{l}\text { General hip, spine and } \\
\text { shoulders movilization } \\
\text { recruiting body's center } \\
\text { deep stabilizers }\end{array}$} & \multirow{3}{*}{$\begin{array}{l}\text { General hip, spine and } \\
\text { shoulders movilization with } \\
\text { transfer to the principal } \\
\text { exercises }\end{array}$} & \multirow{3}{*}{$\begin{array}{l}4-6 \\
\text { repetitions/exe } \\
\text { rcise }\end{array}$} & $\begin{array}{l}\text { Breathing 1-1-1- } \\
1 \text { (lower } \\
\text { execution } \\
\text { velocity) } \\
\end{array}$ & \multirow{3}{*}{$\begin{array}{c}\text { Work/rest } \\
\text { quotient of } 1 / 4\end{array}$} \\
\hline & & & & $\begin{array}{l}\text { No additional } \\
\text { weight }\end{array}$ & \\
\hline & & & & $\begin{array}{l}\text { OMNI-Res score } \\
\text { of } 4-6 \text { points }\end{array}$ & \\
\hline \multirow{3}{*}{$\begin{array}{l}\text { MESOCYCLE } 1 \\
\text { (WEEKS 3-6) }\end{array}$} & \multirow{3}{*}{$\begin{array}{l}\text { Standing pelvic clock. } \\
\text { standing spine twist. } \\
\text { standing hip extension. } \\
\text { hip abduction seated on a } \\
\text { chair. windmill arms } \\
\text { seated on a chair. } \\
\text { standing floating arms. }\end{array}$} & \multirow{3}{*}{$\begin{array}{l}\text { Sitting and standing from a } \\
\text { chair. standing bent over } \\
\text { row. ankle flexion- } \\
\text { extension grabbing the } \\
\text { back of the chair. arm side } \\
\text { lateral. standing push the } \\
\text { partner for chest and } \\
\text { biceps. curl ups. }\end{array}$} & \multirow{3}{*}{$\begin{array}{l}6-8 \\
\text { repetitions/exe } \\
\text { rcise }\end{array}$} & $\begin{array}{l}\text { Breathing 1-1-1- } \\
1 \text { (lower } \\
\text { execution } \\
\text { velocity) }\end{array}$ & \multirow{3}{*}{$\begin{array}{l}\text { Work/rest } \\
\text { quotient of } 1 / 2\end{array}$} \\
\hline & & & & $\begin{array}{l}\text { No additional } \\
\text { weight }\end{array}$ & \\
\hline & & & & $\begin{array}{l}\text { OMNI-Res score } \\
\text { of } 6-7 \text { points }\end{array}$ & \\
\hline \multirow{3}{*}{$\begin{array}{l}\text { MESOCYCLE } 2 \\
(\text { WEEKS 7-10) }\end{array}$} & \multirow{3}{*}{$\begin{array}{l}\text { Supine circle leg lifts. } \\
\text { supine leg swing. supine } \\
\text { up shoulders with elastic } \\
\text { band. supine curl ups with } \\
\text { chi ball. side leg lifts. } \\
\text { standing shoulder circles } \\
\text { with chi ball. standing } \\
\text { lateral flexion. }\end{array}$} & \multirow{3}{*}{$\begin{array}{l}\text { Squat grabbing the back of } \\
\text { the chair. standing bent } \\
\text { over row. ankle flexion- } \\
\text { extension grabbing the } \\
\text { back of the chair. arm side } \\
\text { lateral. dumbbell press and } \\
\text { biceps seated on a chair. } \\
\text { standing triceps. curl ups. } \\
\text { Elastic band for trunk and } \\
\text { upper extremities exercises. }\end{array}$} & \multirow{3}{*}{$\begin{array}{l}8-10 \\
\text { repetitions/exe } \\
\text { rcise }\end{array}$} & $\begin{array}{l}\text { Breathing 1-1-1- } \\
1 \text { (medium } \\
\text { execution } \\
\text { velocity) }\end{array}$ & \multirow{3}{*}{$\begin{array}{l}\text { Work/rest } \\
\text { quotient of } \\
1 / 1.5\end{array}$} \\
\hline & & & & $\begin{array}{l}\text { Additional light- } \\
\text { weight: elastic } \\
\text { band }\end{array}$ & \\
\hline & & & & $\begin{array}{l}\text { OMNI-Res score } \\
\text { of } 7-8 \text { points }\end{array}$ & \\
\hline \multirow{3}{*}{$\begin{array}{l}\text { MESOCYCLE } 3 \\
(\text { WEEKS 11-14) }\end{array}$} & \multirow{3}{*}{$\begin{array}{l}\text { The bridge. side leg lifts } \\
\text { with chi ball. prone hip } \\
\text { extension. the cat with } \\
\text { elastic band. supine } \\
\text { windmill arms with } \\
\text { elastic band. standing } \\
\text { rolldowns. the hundred } \\
\text { standing with elastic } \\
\text { band. }\end{array}$} & \multirow{3}{*}{$\begin{array}{l}\text { Squat. standing bent over } \\
\text { row. lunges. arm side } \\
\text { lateral. dumbbell press and } \\
\text { biceps seated on a chair. } \\
\text { standing triceps. curl ups. } \\
\text { Elastic band for trunk and } \\
\text { upper extremities exercises. }\end{array}$} & \multirow{3}{*}{$\begin{array}{l}10-12 \\
\text { repetitions/exe } \\
\text { rcise }\end{array}$} & $\begin{array}{l}\text { Breathing 1-1 } \\
\text { (higher execution } \\
\text { velocity) }\end{array}$ & \multirow{3}{*}{$\begin{array}{l}\text { Work/rest } \\
\text { quotient of } 1 / 1\end{array}$} \\
\hline & & & & $\begin{array}{l}\text { Additional } \\
\text { moderate-weight: } \\
\text { elastic band }\end{array}$ & \\
\hline & & & & $\begin{array}{l}\text { OMNI-Res score } \\
\text { of } 8-9 \text { points }\end{array}$ & \\
\hline $\begin{array}{l}\text { MESOCYCLE } 4 \\
(\text { WEEKS 15-18) }\end{array}$ & $\begin{array}{l}\text { Combining femur arcs } \\
\text { and windmill arms. pelvic } \\
\text { curl with elastic band. } \\
\text { combining curl ups and } \\
\text { shoulder abduction with } \\
\text { elastic band. side leg } \\
\text { kicks. diamond press. } \\
\text { acsicted rnll wn writh }\end{array}$ & $\begin{array}{l}\text { Squat and front arms. } \\
\text { standing bent over row. } \\
\text { lunges and up arms. arm } \\
\text { side lateral. dumbbell press } \\
\text { and biceps seated on a } \\
\text { chair. standing triceps. curl } \\
\text { ups. Elastic band for trunk } \\
\text { and upper extremities }\end{array}$ & $\begin{array}{l}12 \\
\text { repetitions/exe } \\
\text { rcise }\end{array}$ & $\begin{array}{l}\text { Breathing 1-1 } \\
\text { (higher execution } \\
\text { velocity) }\end{array}$ & $\begin{array}{l}\text { Work/rest } \\
\text { quotient of } \\
1 / 0.5\end{array}$ \\
\hline
\end{tabular}




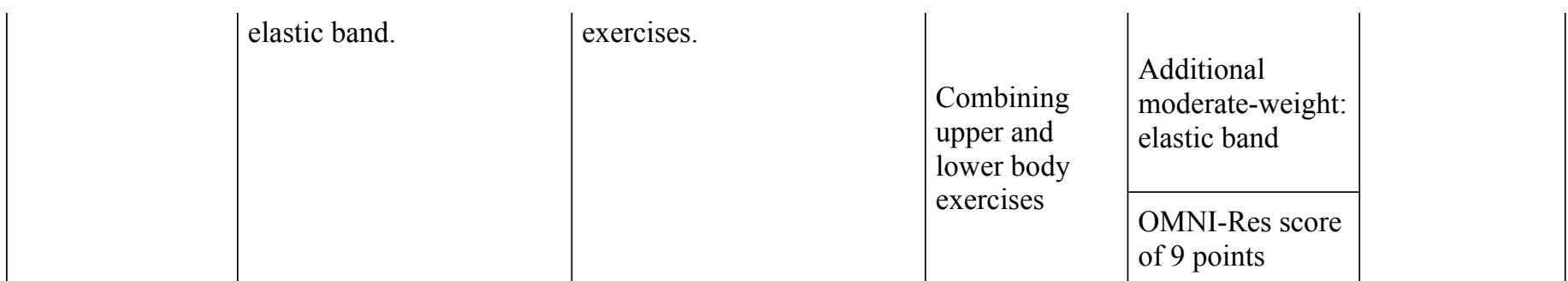

Note: OMIN-Res= OMNI-Resistance Exercise Scale of perceived exertion; Breathing 1-1-1-1: inhale to prepare the movementexhale to go to the final position-inhale in the final position-exhale to go back to initial position. Breathing 1-1: inhale to prepare and go to the final position- exhale to go back to initial position. 
Table 2 (on next page)

Sample characteristics at baseline $(n=60)$ 
Table 2. Sample characteristics at baseline $(n=60)$

\begin{tabular}{|c|c|c|c|c|c|c|}
\hline Variables & $\mathbf{n}$ & Mean & SD & Min & $\operatorname{Max}$ & $\mathbf{p}$ \\
\hline \multicolumn{7}{|l|}{ Age (years) } \\
\hline Pilates & 20 & 67.50 & 3.87 & 62 & 78 & \multirow{3}{*}{$0.000003^{\wedge \prime \prime}$} \\
\hline Muscular & 20 & 73.36 & 4.84 & 62 & 80 & \\
\hline Control & 20 & 65.89 & 4.54 & 60 & 76 & \\
\hline \multicolumn{7}{|c|}{ Height (cm) } \\
\hline Pilates & 20 & 152.1 & 6.24 & 138.2 & 164.6 & \multirow{3}{*}{0.718} \\
\hline Muscular & 20 & 150.10 & 6.02 & 140 & 164.2 & \\
\hline Control & 20 & 154.41 & 6.88 & 140 & 165 & \\
\hline \multicolumn{7}{|c|}{ Weight (kg) } \\
\hline Pilates & 20 & 74.62 & 11.65 & 56.8 & 94.8 & \multirow{3}{*}{0.108} \\
\hline Muscular & 20 & 71.98 & 11.95 & 53.6 & 101.2 & \\
\hline Control & 20 & 72.03 & 11.43 & 51.7 & 99.3 & \\
\hline \multicolumn{7}{|c|}{ BMI $\left(\mathrm{kg} / \mathrm{m}^{2}\right)$} \\
\hline Pilates & 20 & 32.32 & 5.24 & 25.38 & 42.42 & \multirow{3}{*}{0.576} \\
\hline Muscular & 20 & 31.95 & 4.84 & 24.86 & 43.88 & \\
\hline Control & 20 & 30.54 & 6.36 & 19.46 & 41.12 & \\
\hline \multicolumn{7}{|l|}{ SB_time (s) } \\
\hline Pilates & 20 & 14.18 & 8.50 & 1 & 30 & \multirow{3}{*}{0.849} \\
\hline Muscular & 20 & 12.96 & 9.84 & 1.38 & 30 & \\
\hline Control & 20 & 14.77 & 12.32 & 2.5 & 30 & \\
\hline \multicolumn{7}{|c|}{$\mathrm{SB} \_V m l(\mathbf{m m} / \mathbf{s})$} \\
\hline Pilates & 20 & 3.12 & 2.67 & 0.41 & 9.96 & \multirow{3}{*}{0.585} \\
\hline Muscular & 20 & 2.53 & 2.11 & 0.23 & 7 & \\
\hline Control & 20 & 2.34 & 2.56 & 0.18 & 7.7 & \\
\hline \multicolumn{7}{|c|}{ SB_Vap $(\mathrm{mm} / \mathrm{s})$} \\
\hline Pilates & 20 & 5.11 & 4.67 & 0.79 & 15.64 & \multirow{3}{*}{0.485} \\
\hline Muscular & 20 & 3.83 & 2.61 & 0.25 & 9.24 & \\
\hline Control & 20 & 3.86 & 4.04 & 0.2 & 11.85 & \\
\hline \multicolumn{7}{|c|}{ SB_Varea $\left(\mathrm{mm} / \mathrm{s}^{2}\right)$} \\
\hline Pilates & 20 & 2.58 & 2.26 & 0.34 & 8.34 & \multirow{3}{*}{0.87} \\
\hline Muscular & 20 & 2.3 & 1.92 & 0.14 & 6.96 & \\
\hline Control & 20 & 2.23 & 2.45 & 0.11 & 6.77 & \\
\hline \multicolumn{7}{|l|}{ TUG (s) } \\
\hline Pilates & 20 & 6.99 & 0.79 & 5.55 & 8.76 & \multirow{3}{*}{$0.00038^{* \wedge}$} \\
\hline Muscular & 20 & 8.16 & 1.42 & 6.46 & 10.9 & \\
\hline Control & 20 & 8.54 & 1.23 & 6.61 & 11.3 & \\
\hline
\end{tabular}

Tisom_Flw (N/m) 


\begin{tabular}{|c|c|c|c|c|c|c|}
\hline Pilates & 20 & 198.53 & 78.4 & 51.21 & 365.45 & \multirow{3}{*}{0.222} \\
\hline Muscular & 20 & 234.66 & 67.0 & 125.1 & 368.47 & \\
\hline Control & 20 & 231.24 & 70.8 & 95.93 & 415.86 & \\
\hline \multicolumn{7}{|c|}{ Tisom_Exw (N/m) } \\
\hline Pilates & 20 & 78.96 & 29.0 & 17.84 & 128.79 & \multirow{3}{*}{0.723} \\
\hline Muscular & 20 & 80.1 & 26.7 & 36.97 & 129.41 & \\
\hline Control & 20 & 86.64 & 38.6 & 18.57 & 153.38 & \\
\hline \multicolumn{7}{|c|}{ Hisom_Flw (N/m) } \\
\hline Pilates & 20 & 43.18 & 12.8 & 13.21 & 61.22 & \multirow{3}{*}{0.491} \\
\hline Muscular & 20 & 45.66 & 18.6 & 12.64 & 74.96 & \\
\hline Control & 20 & 51.1 & 28.7 & 20.55 & 145.72 & \\
\hline \multicolumn{7}{|c|}{ Hisom_Exw N/m } \\
\hline Pilates & 20 & 100.19 & 24.6 & 53.28 & 152.75 & \multirow{3}{*}{0.586} \\
\hline Muscular & 20 & 111.83 & 47.8 & 38.18 & 248.06 & \\
\hline Control & 20 & 106.81 & 30.3 & 38.37 & 158.67 & \\
\hline \multicolumn{7}{|c|}{ Hisok_Fl60w (N/m) } \\
\hline Pilates & 20 & 43.94 & 11.3 & 26.3 & 65 & \multirow{3}{*}{0.723} \\
\hline Muscular & 20 & 40.39 & 18.8 & 14.16 & 73.06 & \\
\hline Control & 20 & 43.94 & 18.0 & 17.26 & 76.79 & \\
\hline \multicolumn{7}{|c|}{ Hisok_Fl120w (N/m) } \\
\hline Pilates & 20 & 39.49 & 14.9 & 11.2 & 71.82 & \multirow{3}{*}{0.351} \\
\hline Muscular & 20 & 33.07 & 17.1 & 6.95 & 66.84 & \\
\hline Control & 20 & 39.56 & 17.4 & 13.77 & 66.12 & \\
\hline \multicolumn{7}{|c|}{ Hisok_Ex60w (N/m) } \\
\hline Pilates & 20 & 61.67 & 22.1 & 30.88 & 107.37 & \multirow{3}{*}{0.111} \\
\hline Muscular & 20 & 47.34 & 20.2 & 12.39 & 84.33 & \\
\hline Control & 20 & 57.29 & 24.8 & 25.09 & 107.93 & \\
\hline \multicolumn{7}{|c|}{ Hisok_Ex120w (N/m) } \\
\hline Pilates & 20 & 35 & 18.0 & 10.75 & 72.44 & \multirow{3}{*}{0.378} \\
\hline Muscular & 20 & 35.47 & 17.6 & 8.47 & 79.57 & \\
\hline Control & 20 & 43.61 & 27.4 & 10.8 & 127.64 & \\
\hline
\end{tabular}

Note: $\mathrm{SD}=$ Standard Deviation; $\mathrm{BMI}=\mathrm{kg} / \mathrm{m}^{2} ; \mathrm{SB}$ time: time maintaining right monopodal static position; SB_Vml: right monopodal displacement velocity in medial-lateral plane; SB_Vap: right monopodal displacement velocity in antero-posterior plane; SB_area: right monopodal velocity moment; TUG: timed up and go; Tisom_Flw=isometric trunk flexion relative to weight; Tisom_Exw= isometric trunk extension relative to weight; Hisom_Flw=isometric hip flexion relative to weight; Hisom_Exw=isometric hip extension relative to weight; Hisok_Fl60w=isokinetic hip flexion at $60^{\circ} / \mathrm{sg}$ relative to weight; Hisok_Fl120w=isokinetic hip flexion at $120^{\circ} / \mathrm{sg}$ relative to weight; Hisok_Ex $60 \mathrm{w}=$ isokinetic hip extension at $60 \%$ sg relative to weight; Hisok_Ex $120 \mathrm{w}=$ isokinetic hip extension at $120^{\circ} / \mathrm{sg}$ relative to weight.

$\wedge \mathrm{p}<0.05$ differences between muscular group and Pilates group

$" p<0.05$ differences between muscular group and control group

$* \mathrm{p}<0.05$ differences between control group and Pilates group 
1

Peer] reviewing PDF | (2019:05:37526:3:0:NEW 20 Sep 2019) 
Table 3(on next page)

Trunk and hip isometric strength parameters. Differences between Pilates, Muscular and Control groups 
1 Table 3. Trunk and hip isometric strength parameters. Differences between Pilates, Muscular and Control groups.

\begin{tabular}{|c|c|c|c|c|c|c|c|c|c|c|c|c|c|}
\hline \multirow{3}{*}{$\begin{array}{l}\text { Primary } \\
\text { Outcomes }\end{array}$} & \multirow{3}{*}{$\begin{array}{c}\mathbf{n} \\
(\mathrm{ITT})\end{array}$} & \multirow{3}{*}{$\begin{array}{c}\mathrm{n} \\
\text { (Completer) }\end{array}$} & \multirow{3}{*}{$\begin{array}{c}\text { Mean of } \\
\text { the } \\
\text { difference }\end{array}$} & \multirow{3}{*}{$\begin{array}{l}\text { SD of the } \\
\text { difference }\end{array}$} & \multicolumn{9}{|c|}{ ANCOVA interactions $\left(F, p, E S \eta^{2}\right)$} \\
\hline & & & & & \multicolumn{3}{|c|}{ Training * Group } & \multicolumn{3}{|c|}{ Training $*$ Baseline } & \multicolumn{3}{|c|}{ Training * Age } \\
\hline & & & & & $\mathrm{F}$ & $\mathrm{p}$ & $\mathrm{ES} \eta^{2}$ & $\mathrm{~F}$ & $\mathrm{p}$ & $\mathrm{ES} \eta^{2}$ & $\mathrm{~F}$ & $\mathrm{p}$ & $\mathrm{ES} \eta^{2}$ \\
\hline Pilates & 20 & 16 & 24.892 & 89.42 & & & & & & & & & \\
\hline Muscular & 20 & 19 & 9.264 & 55.36 & 0.874 & 0.424 & 0.029 & 3.649 & 0.062 & 0.061 & 1.172 & 0.284 & 0.02 \\
\hline Control & 20 & 14 & 23.797 & 64.65 & & & & & & & & & \\
\hline Pilates & 20 & 16 & 10.227 & 20.02 & & & & & & & & & \\
\hline Muscular & 20 & 19 & 17.094 & 31.85 & 1.24 & 0.297 & 0.041 & 1.358 & 0.249 & 0.023 & 0.901 & 0.247 & 0.015 \\
\hline Control & 20 & 14 & -2.071 & 18.97 & & & & & & & & & \\
\hline \multicolumn{14}{|c|}{ Hisom_Flw N/m } \\
\hline Pilates & 20 & 16 & 4.176 & 11.37 & & & & & & & & & \\
\hline Muscular & 20 & 19 & 19.171 & 24.45 & 5.833 & 0.005 & 0.172 & 0.813 & 0.371 & 0.012 & 0.176 & 0.676 & 0.003 \\
\hline Control & 20 & 14 & 7.815 & 18.36 & & & & & & & & & \\
\hline
\end{tabular}

Note: $\mathrm{SD}=$ Standard Deviation; ITT=Intention to treat; Tisom Flw=isometric trunk flexion relative to weight; Tisom Exw= isometric trunk extension relative to weight; Hisom_Flw=isometric hip flexion relative to weight; Hisom_Exw=isometric hip extension relative to weight. 
Table 4 (on next page)

Trunk and hip isokinetic strength parameters. Differences between Pilates, Muscular and Control groups 
1 Table 4. Trunk and hip isokinetic strength parameters. Differences between Pilates, Muscular and Control groups.

\begin{tabular}{|c|c|c|c|c|c|c|c|c|c|c|c|c|c|}
\hline \multirow{3}{*}{$\begin{array}{l}\text { Primary } \\
\text { Outcomes }\end{array}$} & \multirow{3}{*}{$\begin{array}{c}\mathbf{n} \\
(\text { ITT })\end{array}$} & \multirow{3}{*}{$\begin{array}{c}n \\
\text { (Completer) }\end{array}$} & \multirow{3}{*}{$\begin{array}{l}\text { Mean of } \\
\text { the } \\
\text { difference }\end{array}$} & \multirow{3}{*}{$\begin{array}{l}\text { SD of the } \\
\text { difference }\end{array}$} & \multicolumn{9}{|c|}{ ANCOVA interactions $\left(F, p, E S \eta^{2}\right)$} \\
\hline & & & & & \multicolumn{3}{|c|}{ Training $*$ Group } & \multicolumn{3}{|c|}{ Training $*$ Baseline } & \multicolumn{3}{|c|}{ Training $*$ Age } \\
\hline & & & & & $\mathrm{F}$ & $\mathrm{p}$ & $\mathrm{ES} \eta^{2}$ & $\mathrm{~F}$ & $\mathrm{p}$ & $\mathrm{ES} \eta^{2}$ & $\mathrm{~F}$ & $\mathrm{p}$ & $\mathrm{ES} \eta^{2}$ \\
\hline \multicolumn{14}{|l|}{$\begin{array}{c}\text { Hisok_Fl60w } \\
(\mathrm{N} / \mathrm{m})\end{array}$} \\
\hline Pilates & 20 & 16 & 6.705 & 11.23 & & & & & & & & & \\
\hline Muscular & 20 & 19 & 13.786 & 11.5 & 1.015 & 0.369 & 0.035 & 1.149 & 0.288 & 0.02 & 0.301 & 0.585 & 0.005 \\
\hline Control & 20 & 14 & 5.658 & 15.82 & & & & & & & & & \\
\hline \multicolumn{14}{|l|}{$\begin{array}{c}\text { Hisok_Fl120w } \\
(\bar{N} / \mathrm{m})\end{array}$} \\
\hline Pilates & 20 & 16 & 5.941 & 11.98 & & & & & & & & & \\
\hline Muscular & 20 & 19 & 12.27 & 12.92 & 17.53 & 0.183 & 0.06 & 0.143 & 0.707 & 0.002 & 0.058 & 0.81 & 0.001 \\
\hline Control & 20 & 14 & 5.444 & 14.04 & & & & & & & & & \\
\hline \multicolumn{14}{|l|}{$\begin{array}{c}\text { Hisok_Ex60w } \\
(\mathrm{N} / \mathrm{m})\end{array}$} \\
\hline Pilates & 20 & 16 & 0.801 & 26.15 & & & & & & & & & \\
\hline Muscular & 20 & 19 & 15.541 & 19.9 & 0.872 & 0.424 & 0.028 & 467.6 & 0.035 & 0.076 & 0.002 & 0.967 & 0 \\
\hline Control & 20 & 14 & 6.965 & 25.95 & & & & & & & & & \\
\hline \multicolumn{14}{|l|}{$\begin{array}{l}\text { Hisok_Ex120w } \\
(\overline{\mathrm{N}} / \mathrm{m})\end{array}$} \\
\hline Pilates & 20 & 16 & 2.716 & 14.22 & & & & & & & & & \\
\hline Muscular & 20 & 19 & 8.876 & 17.7 & 0.742 & 0.481 & 0.026 & 12.924 & 0.261 & 0.022 & 0.022 & 0.881 & 0 \\
\hline Control & 20 & 14 & 0.336 & 14.88 & & & & & & & & & \\
\hline
\end{tabular}

Note: $\mathrm{SD}=$ Standard Deviation; ITT=Intention to treat; Hisok Fl $60 \mathrm{w}=$ isokinetic hip flexion at $60^{\circ} / \mathrm{sg}$ relative to weight; Hisok Fl120w=isokinetic hip flexion at $120^{\circ} / \mathrm{sg}$ relative to weight; Hisok_Ex60w=isokinetic hip extension at $60^{\circ} / \mathrm{sg}$ relative to weight; Hisok_Ex $120 \mathrm{w}=$ isokinetic hip extension at $120^{\circ} / \mathrm{sg}$ relative to weight. 


\section{Table 5 (on next page)}

Static and dynamic balance parameters. Differences between Pilates, Muscular and Control groups 
1 Table 5. Static and dynamic balance parameters. Differences between Pilates, Muscular and Control groups.

\begin{tabular}{|c|c|c|c|c|c|c|c|c|c|c|c|c|c|}
\hline \multirow{3}{*}{$\begin{array}{l}\text { Secondary } \\
\text { Outcomes }\end{array}$} & \multirow{3}{*}{ n (ITT) } & \multirow{3}{*}{$\begin{array}{c}\mathbf{n} \\
\text { (Completer) }\end{array}$} & \multirow{3}{*}{$\begin{array}{l}\text { Mean of the } \\
\text { difference }\end{array}$} & \multirow{3}{*}{$\begin{array}{l}\text { SD of the } \\
\text { difference }\end{array}$} & \multicolumn{9}{|c|}{ ANCOVA interactions $\left(F, p, E S \eta^{2}\right)$} \\
\hline & & & & & \multicolumn{3}{|c|}{ Training $*$ Group } & \multicolumn{3}{|c|}{ Training $*$ Baseline } & \multicolumn{3}{|c|}{ Training $*$ Age } \\
\hline & & & & & $\mathrm{F}$ & $\mathrm{p}$ & $\mathrm{ES} \eta^{2}$ & $\mathrm{~F}$ & $\mathrm{p}$ & $\mathrm{ES} \eta^{2}$ & $\mathrm{~F}$ & $\mathrm{p}$ & $\mathrm{ES} \eta^{2}$ \\
\hline \multicolumn{14}{|l|}{ SB_time (s) } \\
\hline Pilates & 20 & 16 & 0.501 & 10.87 & & & & & & & & & \\
\hline Muscular & 20 & 19 & 1.824 & 8.06 & 1.73 & 0.187 & 0.041 & 18.33 & 0.001 & 0.217 & 7.7 & 0.008 & 0.091 \\
\hline Control & 20 & 14 & 1.121 & 4.08 & & & & & & & & & \\
\hline \multicolumn{14}{|c|}{ SB_Vml $(\mathrm{mm} / \mathrm{s})$} \\
\hline Pilates & 20 & 16 & -0.496 & 3.40 & & & & & & & & & \\
\hline Muscular & 20 & 19 & 0.102 & 1.44 & 0.546 & 0.582 & 0.012 & 27.356 & $<0.001$ & 0.306 & 5.992 & 0.018 & 0.067 \\
\hline Control & 20 & 14 & -0.104 & 1.5 & & & & & & & & & \\
\hline \multicolumn{14}{|c|}{ SB_Vap $(\mathrm{mm} / \mathrm{s})$} \\
\hline Pilates & 20 & 16 & -0.541 & 5.71 & & & & & & & & & \\
\hline Muscular & 20 & 19 & 0.91 & 3.11 & 0.38 & 0.686 & 0.009 & 27.466 & $<0.001$ & 0.311 & 5.171 & 0.027 & 0.059 \\
\hline Control & 20 & 14 & 0.302 & 2.59 & & & & & & & & & \\
\hline \multicolumn{14}{|l|}{$\begin{array}{c}\text { SB_Varea } \\
\left(\mathrm{mm} / \mathrm{s}^{2}\right)\end{array}$} \\
\hline Pilates & 20 & 16 & -0.215 & 2.7 & & & & & & & & & \\
\hline Muscular & 20 & 19 & 0.433 & 1.86 & 0.086 & 0.917 & 0.002 & 237.979 & $<0.001$ & 0.282 & 55.158 & 0.022 & 0.065 \\
\hline Control & 20 & 14 & -0.19 & 1.22 & & & & & & & & & \\
\hline \multicolumn{14}{|l|}{ TUG (s) } \\
\hline Pilates & 20 & 16 & -0.261 & 0.46 & & & & & & & & & \\
\hline Muscular & 20 & 19 & -0.677 & 0.87 & 2.359 & 0.104 & 0.067 & 9.798 & 0.003 & 0.140 & 0.5 & 0.482 & 0.007 \\
\hline Control & 20 & 14 & -0.301 & 0.68 & & & & & & & & & \\
\hline
\end{tabular}


Note: $\mathrm{SD}=$ Standard Deviation; ITT=Intention to treat; $\mathrm{SB}$ time: time maintaining right monopodal static position; SB_Vml: right monopodal displacement velocity in medial-lateral plane; SB_Vap: right monopodal displacement velocity in antero-posterior plane; SB_area: right monopodal velocity moment; TUG: timed up and go. 
Table 6(on next page)

Trunk and hip isometric and isokinetic strength parameters pre- and post- intervention in Pilates, Muscular and Control groups 
1 Table 6. Trunk and hip isometric and isokinetic strength parameters pre- and post- intervention in Pilates,

2 Muscular and Control groups.

\begin{tabular}{|c|c|c|c|c|c|c|c|c|c|c|}
\hline \multirow[t]{2}{*}{ Variables } & \multicolumn{2}{|c|}{ Pre-training } & \multicolumn{4}{|c|}{ Post-Training } & \multirow[t]{2}{*}{$p$} & \multicolumn{2}{|c|}{$\begin{array}{l}\text { 95\% CI for } \\
\text { Mean Difference }\end{array}$} & \multirow[t]{2}{*}{ Cohen's d } \\
\hline & $\mathbf{n}$ & Mean & SD & $\mathbf{n}$ & Mean & SD & & Lower & Upper & \\
\hline \multicolumn{11}{|c|}{ Tisom_Flw N/m } \\
\hline Pilates & 20 & 198,53 & 78,4 & 16 & 251 & 91,3 & 0,231 & $-84,19$ & 21,96 & 0,64 \\
\hline Muscular & 20 & 234,66 & 67,0 & 19 & 245,97 & 72,0 & 0,441 & $-39,48$ & 18,03 & 0,19 \\
\hline Control & 20 & 231,24 & 70,8 & 14 & 272,65 & 109,3 & 0,14 & $-72,39$ & 11,2 & 0,91 \\
\hline \multicolumn{11}{|c|}{ Tisom_Exw N/m } \\
\hline Pilates & 20 & 78,96 & 29,0 & 16 & 97,14 & 31,3 & $\mathbf{0 , 0 3 3}$ & $-24,37$ & $-1,19$ & 0,60 \\
\hline Muscular & 20 & 80,1 & 26,7 & 19 & 100,77 & 43,0 & 0,019 & $-35,98$ & $-3,61$ & 0,82 \\
\hline Control & 20 & 86,64 & 38,6 & 14 & 84,97 & 34,2 & 0,653 & $-9,84$ & 15,17 & 0,23 \\
\hline \multicolumn{11}{|c|}{ Hisom_Flw N/m } \\
\hline Pilates & 20 & 43,18 & 12,8 & 16 & 50,4 & 15,3 & 0,117 & $-11,92$ & 1,48 & 0,51 \\
\hline Muscular & 20 & 45,66 & 18,6 & 19 & 48,48 & 20,5 & 0,37 & $-8,31$ & 3,25 & 0,25 \\
\hline Control & 20 & 51,1 & 28,7 & 14 & 55,76 & 32,0 & 0,089 & $-7,65$ & 0,62 & 0,01 \\
\hline \multicolumn{11}{|c|}{ Hisom_Exw N/m } \\
\hline Pilates & 20 & 100,19 & 24,6 & 16 & 153,54 & 50,4 & 0,0003 & $-75,55$ & $-28,11$ & 2,06 \\
\hline Muscular & 20 & 111,83 & 47,8 & 19 & 136,79 & 57,4 & 0,001 & $-34,26$ & $-10,13$ & 0,61 \\
\hline Control & 20 & 106,81 & 30,3 & 14 & 112,72 & 44,2 & 0,088 & $-21,83$ & 1,74 & 0,50 \\
\hline \multicolumn{11}{|c|}{ Hisok_Fl60w N/m } \\
\hline Pilates & 20 & 43,94 & 11,3 & 16 & 54,17 & 17,0 & 0,014* & $-14,79$ & $-1,97$ & 0,85 \\
\hline Muscular & 20 & 40,39 & 18,8 & 19 & 58,09 & 21,1 & $0,000004 * *$ & $-21,19$ & $-10,73$ & 1,02 \\
\hline Control & 20 & 43,94 & 18,0 & 14 & 50,63 & 18,4 & 0,149 & $-17,51$ & 2,96 & 0,58 \\
\hline \multicolumn{11}{|c|}{ Hisok_Fl120w N/m } \\
\hline Pilates & 20 & 39,49 & 14,9 & 16 & 48,35 & 18,5 & $0,038 *$ & $-14,37$ & $-0,48$ & 0,57 \\
\hline Muscular & 20 & 33,07 & 17,1 & 19 & 47,88 & 16,7 & $0,0001 * *$ & $-20,41$ & -8 & 0,95 \\
\hline Control & 20 & 39,56 & 17,4 & 14 & 45,15 & 19,9 & 0,119 & $-10,26$ & 9,39 & 0,54 \\
\hline \multicolumn{11}{|c|}{ Hisok_Ex60w N/m } \\
\hline Pilates & 20 & 61,67 & 22,1 & 16 & 63,67 & 38,1 & 0,893 & $-16,68$ & 14,68 & 0,09 \\
\hline Muscular & 20 & 47,34 & 20,2 & 19 & 46,45 & 23,6 & $0,001 * *$ & $-27,82$ & $-8,17$ & 1,03 \\
\hline Control & 20 & 57,29 & 24,8 & 14 & 62,99 & 37,9 & 0,274 & $-25,9$ & 7,99 & 0,39 \\
\hline \multicolumn{11}{|c|}{ Hisok_Ex120w N/m } \\
\hline Pilates & 20 & 35 & 18,0 & 16 & 39,71 & 21,7 & 0,407 & $-11,88$ & 5,09 & 0,25 \\
\hline Muscular & 20 & 35,47 & 17,6 & 19 & 48,34 & 22,8 & $0,031 *$ & $-19,3$ & $-1,26$ & $\mathbf{0 , 7 0}$ \\
\hline Control & 20 & 43,61 & 27,4 & 14 & 37,75 & 21,0 & 0,926 & $-10,26$ & 9,4 & 0,19 \\
\hline
\end{tabular}

3 Note: $\quad \mathrm{SD}=$ Standard Deviation; $\mathrm{PG}=$ Pilates $\quad$ Group; $\mathrm{MG}=$ Muscular Group; $\mathrm{CG}=$ Control Group;

4 Hisok_Fl60w=isokinetic hip flexion at $60 \%$ sg relative to weight; Hisok_Fl120w=isokinetic hip flexion at $120^{\circ} / \mathrm{sg}$

5 relative to weight; Hisok_Ex $60 \mathrm{w}=$ isokinetic hip extension at $60 \%$ sg relative to weight; Hisok_Ex $120 \mathrm{w}=$ isokinetic

6 hip extension at $120^{\circ}$ sg relative to weight. 